\title{
Effects of test levels on creep and relaxation characteristic parameters of stem for rice seedlings grown in plastic cell tray
}

\author{
Jinqing Xiao, Ruijun Ma*, Yu Chen \\ (College of Engineering, South China Agricultural University, Guangzhou 510642, China)
}

\begin{abstract}
Creep and relaxation characteristics of stem for rice seedlings grown in plastic cell tray were studied by static tensile testing, in order to determine the relationship between characteristic parameters (rheological model parameters, stress components and strain components) and test levels (stress levels and strain levels). Rice seedling stem specimen used in the test was $40 \mathrm{~mm}$ in length. And the applied test values for the creep and relaxation test ranged from 1.0-3.0 MPa and $1.5 \%-3.5 \%$, respectively, each for 5 levels. The results indicated that elastic modulus in the creep and relaxation model was not affected by test levels. However, except that viscosity coefficient $\eta_{k v}$ was a constant and $\eta_{m 1}$ decreased with the increase of test levels, other viscosity coefficient and rheological time nonlinearly increased as the test levels increased. And strain components in the creep model and stress components in the relaxation model significantly increased as the test levels increased.
\end{abstract}

Keywords: model parameters, rheological property, stress relaxation, creep property, rice seedling stem, plastic cell tray DOI: $10.25165 /$ j.ijabe.20201304.5673

Citation: Xiao J Q, Ma R J, Chen Y. Effects of test levels on creep and relaxation characteristics parameters of stem for rice seedling grown in plastic cell tray. Int J Agric \& Biol Eng, 2020; 13(4): 19-28.

\section{Introduction}

Rice (Oryza sativa L.) is widely cultivated in China ${ }^{[1]}$. It is the principal food crop in China. And there are greater than $80 \%$ of Chinese people and approximately half of the population of the world who live on rice ${ }^{[2,3]}$. Rice potted-seedling throwing transplanting is one of the three principal agronomic patterns to plant rice in China ${ }^{[4]}$. When the proposed two-degree-of-freedom manipulator type transplanter working in the field ${ }^{[5]}$, rice seedlings were pulled up from the cell tray with clamp-shaped grippers. Rice seedling stem is a kind of biological material and agricultural fiber material with vascular bundle structure ${ }^{[6]}$, composed of cellulose, lignin, hemicellulose and other macromolecules ${ }^{[7,8]}$. It is a known fact that macromolecules would slip between each other when the biological material sample loaded with constant stress or strain $^{[9]}$, causing certain damage to the biological material. Therefore, it is necessary in order to understand the rheological properties of stem for rice seedlings using static tensile testing.

At present, there are some researches on chemical, physical, mechanical and composite materials properties for rice stalk. Song et al. ${ }^{[10]}$ and Ma et al. ${ }^{[11]}$ studied the fracture force of rice seedlings grown in cell tray so as to provide a theoretical basis for designing a transplanter for pulling rice seedlings. Ishimaru ${ }^{[12]}$, Zhang, et al. ${ }^{[13]}$ and Gui et al. ${ }^{[14]}$ studied the relationship between rice stalk lodging resistance and chemical or physical properties. Ghofrani et al. ${ }^{[15]}$ studied the mechanical and physical properties of fiber-cement composite utilizing rice stalk fiber and rice husk ash.

\section{Received date: 2020-01-14 Accepted date: 2020-04-29}

Biographies: Jinqing Xiao, MS, research interests: agricultural mechanization engineering, Email: xiaojq_xjq@163.com. Yu Chen, PhD, Lecturer, research interests: agricultural mechanization and automation research, Email: chenyu219@126.com.

*Corresponding author: Ruijun Ma, $\mathrm{PhD}$, Professor, research interests: agricultural mechanization and automation research. College of Engineering, South China Agricultural University, Guangzhou 510642, China. Tel: +86-13533946196, Email: maruijun_mrj@163.com.
Although these researches study the mechanical properties of the rice stalk, no further studies have been made on the rheological properties of the rice stalk.

Rheological properties of biological materials, including wood, crop stem, fruit, and so on, have been widely studied. Engelund and Salmén ${ }^{[16]}$ studied the effects of different moisture and temperature on the tensile creep and recovery of Norwegian spruce. The results were shown that temperature affected the tensile creep and recovery of Norwegian spruce by affecting all chemical bonds while moisture affected that by affecting hydrogen bonds. And it came to a conclusion that temperature was equally affected by the time-dependent and the elastic response of Norwegian spruce, but moisture had more effect on the time-dependent response than the elastic. Similar researches were also studied by Moutee et al. ${ }^{[17]}$, Gao et al. ${ }^{[9]}$ and Lagafta et al. ${ }^{[18]}$. Creep and stress relaxation properties of hulless barley stem at different moisture contents were studied to find that magnitude of the creep and relaxation curves increased and decreased with the increase of moisture contents, respectively ${ }^{[19]}$. And relaxation fitting models showed that it was better using the 5-element Maxwell model to describe the relaxation behavior of hulless barley stem. Chen et al. ${ }^{[20]}$ investigated wheat straw relaxation behavior with four constitutive models and found that the fractional Zener model was the best model predicting the wheat straw stress relaxation behavior. Further study showed that there was a close relationship between the elasticity and viscosity of wheat straw relaxation behavior and its lignocellulose components. Research of Zhao et al. ${ }^{[21]}$ determined the relaxation parameters of 'Fuji' apple through the generalized Maxwell model. And the relationship between the stress relaxation properties and quality characteristics was also researched. The relaxation cure of pear was fitted with a 3 -element model, and relaxation parameters were obtained ${ }^{[22]}$. In addition, the relationships between relaxation parameters and orientation and location of the pear were also established. However, there are limited studies on rheological properties of rice seedling stem. Ma et al. ${ }^{[5]}$ investigated the rheological properties 
of rice seedling stem, including creep property at $1.5 \mathrm{MPa}$ stress level and stress relaxation property at $2.5 \%$ strain level. By fitting with rheological model equations, respectively, the relevant rheological parameters were obtained, which has been demonstrated that the creep and stress relaxation properties of rice seedling stem can be fitted using the Burgers 4-element model and Maxwell 5-element model. And parameter analysis indicated that certain damage has occurred during the creep and relaxation processes. Nevertheless, the researches on the effects of different test levels on modeling parameters creep and relaxation model parameters of rice seedling stem have not been studied.

Therefore, the main goal of the present work was to investigate the effects of test levels, including stress levels and strain levels, on creep and relaxation characteristic parameters of stem for rice seedlings grown in plastic cell tray. The generated data of creep and relaxation test were fitted with relevant rheological model equations, in order to obtain the creep model and stress relaxation model parameters at different test levels. Furthermore, the relationship between the characteristic parameters (rheological model parameters, stress components, and strain components) and the test levels were also investigated. The results can provide a theoretical basis for damage assessment and relevant simulation analysis of pulling up rice seedlings, as well as agricultural machinery design.

\section{Materials and methods}

\subsection{Materials}

Rice seedling variety selected for testing was Huahang 31 . On June 27th, 2018, the rice seedlings were bred in a plastic cell tray in the test field at Qilin North $\left(113.363^{\circ} \mathrm{E}, 23.167^{\circ} \mathrm{N}\right)$, South China Agricultural University, Guangzhou, China. After completing breeding, the field management was carried out according to the actual situation of the nursery. Rice seedlings after $20 \mathrm{~d}$ (Figure 1), which had 3 to 5 leaves, straight and well-grown stem, were selected as tested seedlings. Samples for testing (Figure 2) were the stems approximately $40 \mathrm{~mm}$ above from the bottom of the rice seedlings.

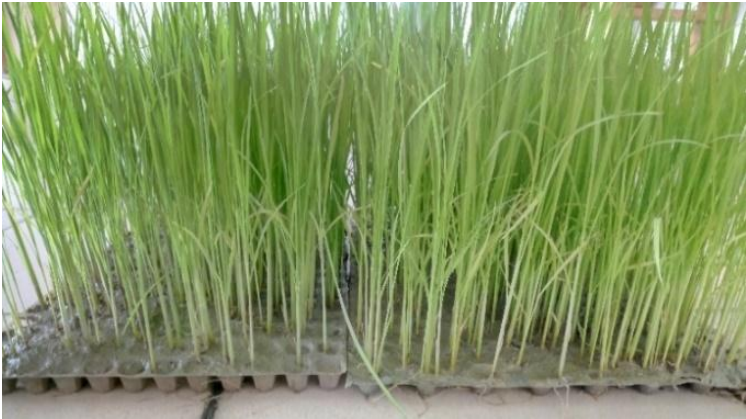

Figure 1 Rice seedlings grown in plastic cell tray

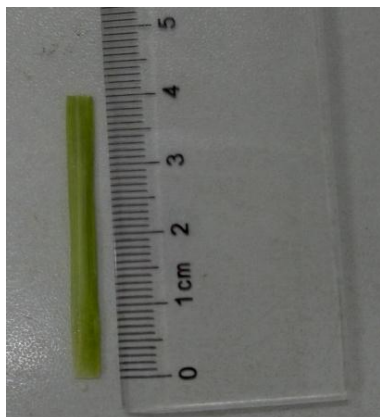

Figure 2 Sample for testing
A vernier caliper with a resolution of $0.02 \mathrm{~mm}$ was used to measure the dimensions of the samples. And the weight of the samples was evaluated using a BMB124 Kunhong High Precision Analytical Balance (HPAB) (Suzhou Kunhong Electronics Co., Ltd., Jiangsu, China) with a resolution of $0.1 \mathrm{mg}$.

The creep and relaxation experiments of rice seedling stem were carried out on Jk-100KE Micro-controlled Universal Electronic Testing Machine (UETM) (Guangzhou Precision Testing Instrument Co., Ltd., Guangzhou, China). Its maximum test force is $100 \mathrm{~N}$, measuring resolution is $0.005 \mathrm{~N}$, and the stress resolution is $0.001 \mathrm{MPa}$.

\subsection{Determination of wet basis moisture content}

The wet weight $m_{w}$ of stem samples was weighted using HPAB Next, stem samples were dried by a JC101 Electric Constant Temperature Drying Cabinet (Nantong Jiacheng Instrument Co., Ltd, Shanghai Chengshun Instrument \& Meter Co., Ltd, Jiangsu \& Shanghai, China) at $105^{\circ} \mathrm{C}$ for $15 \mathrm{~min}$ and then $80^{\circ} \mathrm{C}$ for $4 \mathrm{~h}$. Then, the dry weight $m_{d}$ was also weighted using the analytical balance. The wet basis moisture content was determined by Equation (1):

$$
M C=\frac{m_{w}-m_{d}}{m_{w}} \times 100 \%
$$

The wet basis moisture content of stem samples was $84.47 \% \pm$ $0.69 \%$.

\subsection{Density of rice seedling stem}

Considering the rice seedling stem as solid elliptical biological material, macro axis $a$ and minor axis $b$ of the middle of the sample was measured. And the weight $m$ of the rice seedling stem was weighted by the HPAB. Hence, the density of rice seedling stem samples can be calculated according to Equation (2):

$$
\rho=\frac{4 m}{\pi a b l}
$$

where, $l$ is the measured length of rice seedling stem samples. The average density of 30 tests was $0.7677 \mathrm{~g} / \mathrm{cm}^{3}$.

\subsection{Creep model}

Creep properties of viscoelastic materials are generally described by a 4-element Burgers model, which consists of a Hooke spring, a Newtonian dashpot and a Kelvin body in series ${ }^{[9,23]}$ as seen in Figure 3. A 4-element Burgers model describing the creep behavior of rice seedling stem can be written as follows:

$$
\varepsilon(t)=\sigma_{0}\left(\frac{1}{E_{k}}\left(1-e^{-t / T_{k}}\right)+\frac{1}{E_{k 0}}+\frac{t}{\eta_{k v}}\right)
$$

where, $\sigma_{0}, E_{k}, T_{k}, E_{k 0}$ and $\eta_{k v}$ are coefficients of the 4-element Burgers model; $\sigma_{0}$ is the initial stress; $E_{k}$ is delay elastic modulus; $T_{k}$ is delay time, $T_{k}=\eta_{k} / E_{k}$, and $\eta_{k}$ is delay viscosity coefficient; $E_{k 0}$ is the instant elastic modulus; $\eta_{k v}$ is the viscosity coefficient.

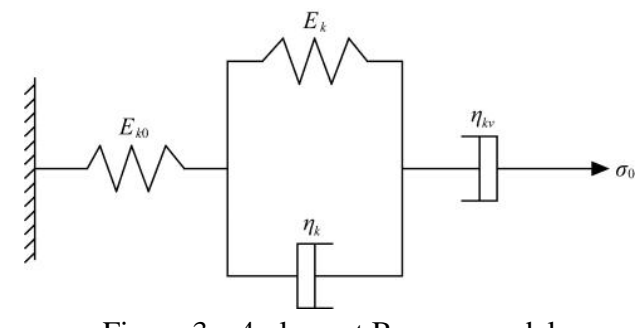

Figure 3 4-element Burgers model

\subsection{Relaxation model}

Relaxation properties of viscoelastic materials are generally described by a generalized Maxwell model, consisting of a Hooke spring and 1 or more maxwell bodies in parallel ${ }^{[24]}$. As seen in Figure 4 , the relaxation property of the rice seedling stem was 
described using a 5-element Maxwell model. This model can be written as follow:

$$
\sigma(t)=\varepsilon_{0}\left(E_{m 1} e^{-t / T_{m 1}}+E_{m 2} e^{-t / T_{m 2}}+E_{m 0}\right)
$$

where, $\varepsilon_{0}, E_{m 1}, E_{m 2}, T_{m 1}, T_{m 2}$ and $E_{\mathrm{m} 0}$ are coefficients of the 5-element Maxwell model; $\varepsilon_{0}$ is the initial strain; $E_{m 1}$ and $E_{m 2}$ are decay elastic modulus of the first Maxwell body (FMB) and the second Maxwell body (SMB); $T_{m 1}$ and $T_{m 2}$ are relaxation time of the first and the second Maxwell body, $T_{m 1}=\eta_{m 1} / E_{m 1}, T_{m 2}=\eta_{m 2} / E_{m 2}$, and $\eta_{m 1}, \eta_{m 2}$ are decay viscosity coefficient of the first and the second Maxwell body; $E_{m 0}$ is the instant elastic modulus.

\subsection{Method}

Creep and relaxation tests on rice seedling stem at 5 stress levels (1.0 MPa, 1.5 MPa, 2.0 MPa, 2.5 MPa, 3.0 MPa) and 5 strain levels $(1.5 \%, 2.0 \%, 2.5 \%, 3.0 \%, 3.5 \%)$, and there were 10 repeated tests at each test level. As shown in Figure 5, the stem sample was clamped between the upper and lower fixtures with a $20 \mathrm{~mm}$ pitch. In the test process, the lower fixture was fixed and the upper clamp moved upward at a certain loading rate. The tensile force was measured S-type force transducer, and the deformation of the stem sample was the displacement of the upper fixture. Then, the force and deformation of the stem sample are displayed on the screen by a computer, and the test data was also recorded.

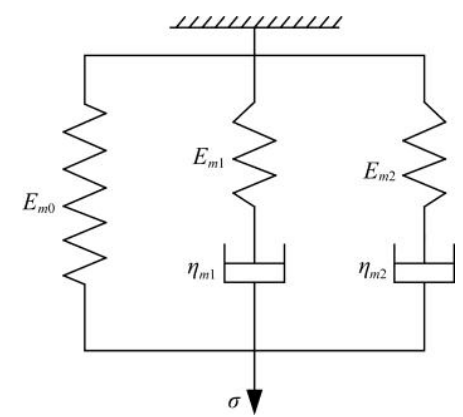

Figure 4 5-element Maxwell model

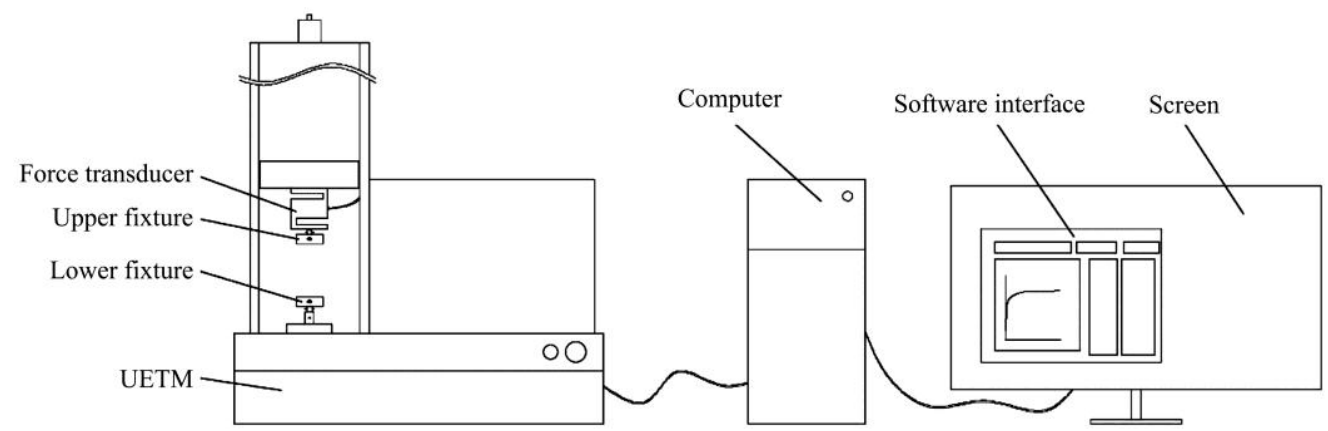

Figure 5 Schematic diagram of test system

\section{Results and discussion}

\subsection{Test results}

The creep tests are presented in Figures 6a-6e and the relaxation tests are presented in Figures 6f-6j. As seen in Figure 6, the creep and relaxation curves were affected by the preset initial tensile load. However, shapes of creep process curves at different stress levels were similar, as well as that of relaxation process curves at different strain levels. In the initial stage of creep and relaxation, the creep and relaxation rate was larger, but with the increase in test time, the creep and relaxation rate decreased nonlinearly, and then the creep strain and the relaxation stress growth rate tended to be stable and the curve tended to be flat.

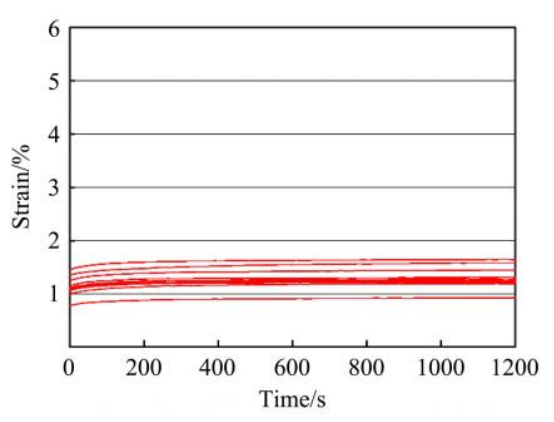

a. $\sigma_{0}=1.0 \mathrm{MPa}$

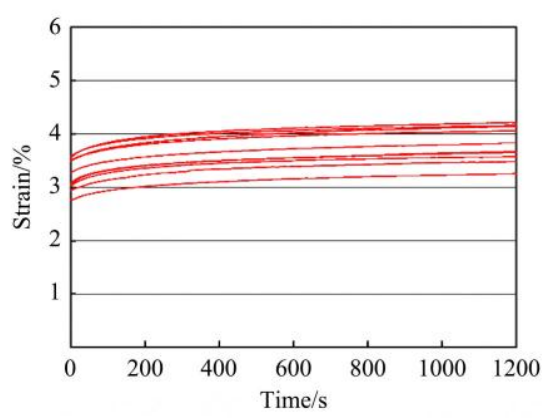

d. $\sigma_{0}=2.5 \mathrm{MPa}$

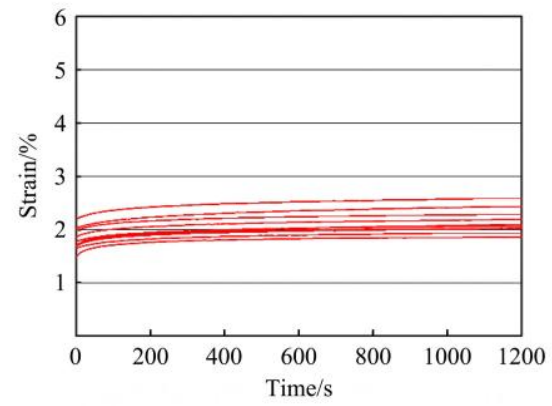

b. $\sigma_{0}=1.5 \mathrm{MPa}$

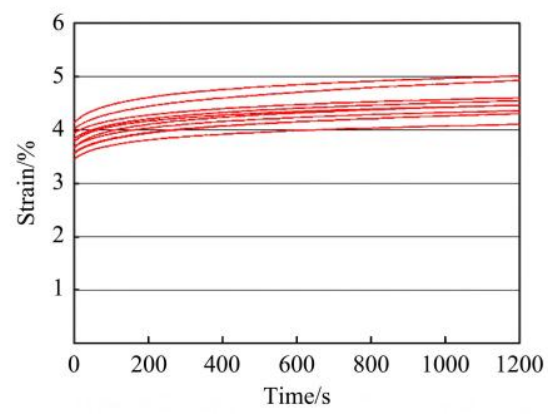

e. $\sigma_{0}=3.0 \mathrm{MPa}$

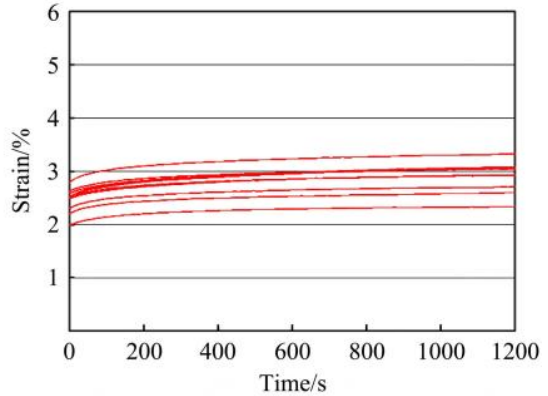

c. $\sigma_{0}=2.0 \mathrm{MPa}$

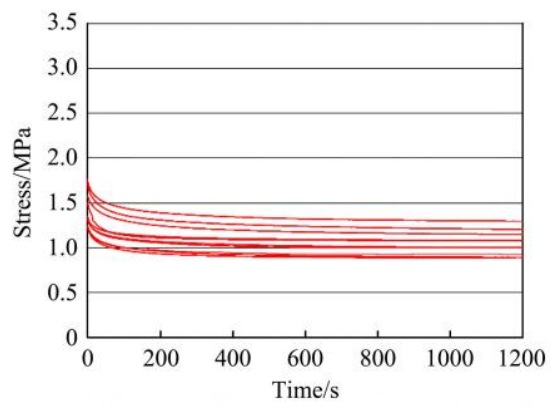

f. $\varepsilon_{0}=1.5 \%$ 

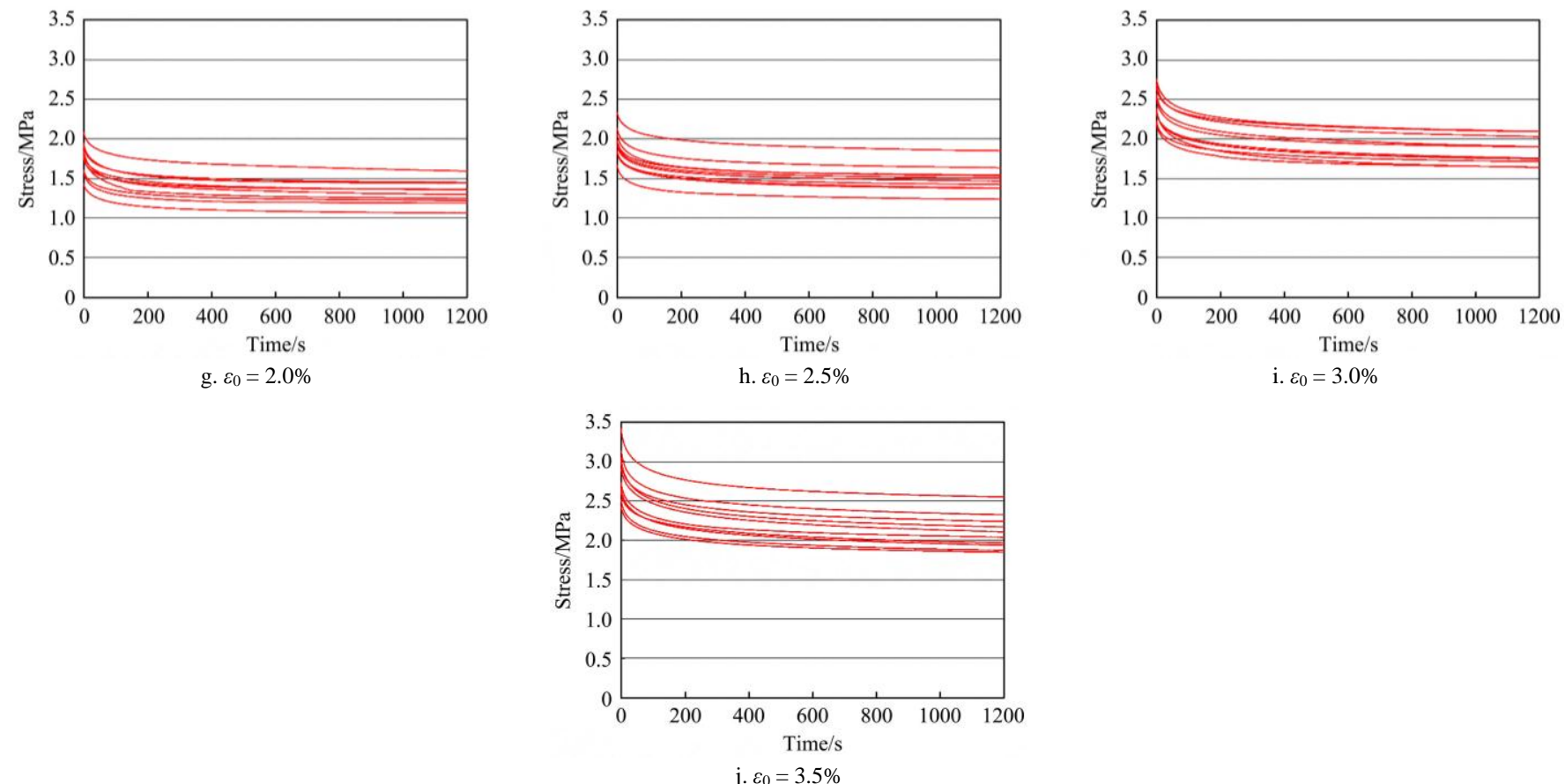

Figure 6 Creep and relaxation test curves at different test levels

As seen in Tables 1 and 2, the creep initial strain, creep quantity, relaxation initial stress and relaxation quantity at different test levels have significant differences $(p<0.05)$. It could be seen from Figure $7 \mathrm{a}$ and Figure 8a that the creep initial strain and relaxation initial stress linearly increased with the increase in test levels. In Figure $7 b$, the creep quantity, meaning the strain increment after the start of creep, linearly increased with the increase of stress as well, which indicated that the rice seedling stem had a large amount of creep quantity as the stress increased, leading to stronger the deformation ductility of rice seedling stem. In Figure 8b, the relaxation quantity, meaning the stress reduction after the start of relaxation, also linearly increased with the increase of strain, which indicated that the rice seedlings had a large amount of relaxation quantity as the strain increased, leading to stronger stress recovery of the stem.

Table 1 Creep initial strain and creep quantity at different stress levels

\begin{tabular}{cccccc}
\hline \multirow{2}{*}{$\begin{array}{c}\text { Stress level } \\
\sigma_{0} / \mathrm{MPa}\end{array}$} & \multicolumn{2}{c}{ Creep initial strain $\varepsilon_{\mathrm{e} 0} / \%$} & & \multicolumn{2}{c}{ Creep quantity $\Delta \varepsilon / \%$} \\
\cline { 2 - 3 } \cline { 5 - 6 } & Rang & Mean $\pm \mathrm{SD}$ & & Range & Mean $\pm \mathrm{SD}$ \\
\hline 1.0 & $0.77-1.45$ & $1.13 \pm 0.188^{\mathrm{e}}$ & & $0.15-0.23$ & $0.18 \pm 0.0285^{\mathrm{e}}$ \\
1.5 & $1.49-2.19$ & $1.81 \pm 0.209^{\mathrm{d}}$ & & $0.29-0.41$ & $0.35 \pm 0.0431^{\mathrm{d}}$ \\
2.0 & $1.99-2.80$ & $2.45 \pm 0.230^{\mathrm{c}}$ & & $0.35-0.55$ & $0.46 \pm 0.0696^{\mathrm{c}}$ \\
2.5 & $2.76-3.59$ & $3.26 \pm 0.295^{\mathrm{b}}$ & & $0.51-0.66$ & $0.58 \pm 0.0501^{\mathrm{b}}$ \\
3.0 & $3.45-4.14$ & $3.77 \pm 0.221^{\mathrm{a}}$ & $0.67-0.91$ & $0.75 \pm 0.0892^{\mathrm{a}}$ \\
\hline Note: & Different & lowercase & letters in the &
\end{tabular}

Note: Different lowercase letters in the same column indicate significant differences at the 0.05 level.

Table 2 Relaxation initial stress and relaxation quantity at different strain levels

\begin{tabular}{cccccc}
\hline \multirow{2}{*}{$\begin{array}{c}\text { Strain levels } \\
\varepsilon_{0} / \%\end{array}$} & \multicolumn{2}{c}{ Relaxation initial stress $\sigma_{\mathrm{e} 0} / \mathrm{MPa}$} & & \multicolumn{2}{c}{ Relaxation quantity $\Delta \sigma / \mathrm{MPa}$} \\
\cline { 2 - 3 } \cline { 5 - 6 } & Range & Average $\pm \mathrm{SD}$ & & Range & Average $\pm \mathrm{SD}$ \\
\hline 1.5 & $1.23-1.76$ & $1.43 \pm 0.20^{\mathrm{e}}$ & & $0.27-0.50$ & $0.37 \pm 0.074^{\mathrm{d}}$ \\
2.0 & $1.42-2.08$ & $1.77 \pm 0.19^{\mathrm{d}}$ & $0.36-0.55$ & $0.45 \pm 0.065^{\mathrm{c}}$ \\
2.5 & $1.67-2.33$ & $1.96 \sim 0.19^{\mathrm{c}}$ & $0.42-0.53$ & $0.46 \pm 0.034^{\mathrm{c}}$ \\
3.0 & $2.20-2.76$ & $2.46 \sim 0.20^{\mathrm{b}}$ & $0.51-0.74$ & $0.61 \pm 0.070^{\mathrm{b}}$ \\
3.5 & $2.42-3.42$ & $2.84 \sim 0.31^{\mathrm{a}}$ & $0.58-0.88$ & $0.74 \pm 0.099^{\mathrm{a}}$ \\
\hline
\end{tabular}

Note: Different lowercase letters in the same column indicate significant differences at the 0.05 level.

\subsection{Relationships between creep model parameters and stress levels}

To obtain creep model parameters, the curves in Figure 6 were fitted by using Equation (3), as shown in Table 3. Using the creep model parameters in Table 3, their relationships with stress levels were analyzed, as seen in Figure 9. In Figure 9a, with the increase of stress $\sigma_{0}$, the delay elastic modulus $E_{k}$ remained basically unchanged, there was the same phenomenon happening on Wang's ${ }^{[25,26]}$ compression creep test on poplar. It revealed that $E_{k}$ had little relationship with the stress level, and it was considered as a constant value, a similar situation also happened in instant elastic modulus, as seen in Figure 9d. Figure 9b shows that the delay viscosity coefficient $\eta_{k}$ had a significant difference $(p<0.05)$ at each stress level. With the increase of $\sigma_{0}$, the delay viscosity coefficient increased with a nonlinear growth rate, and gradually tended to be stable, a similar tendency also happened in delay time $T_{k}$, as seen in Figure 9c. The situation in Figure 9b revealed that the delay viscosity coefficient was nonlinear positive correlated with the stress levels, and the stem had a stronger force to resist deformation and viscous resistance as the stress increased, resulting in the worse fluidity of the internal structure. Figure $9 \mathrm{c}$ shows that the delay time had a nonlinear positive correlation with the stress levels, which revealed that the required time for the Kelvin element in the creep model to reach the strain equilibrium state came to be slower with the stress $\sigma_{0}$ increased. Opposite to delay viscosity coefficient $\eta_{k}$, in Figure $9 \mathrm{e}$, the viscosity coefficient $\eta_{k}$ was followed by a nonlinear reduction trend with a decreasing rate of decline. It showed that the viscosity coefficient had a nonlinear negative correlation with the stress levels, which indicated that the stem had a weaker force to resist deformation and viscous resistance as the stress increased, leading to the better fluidity of the internal structure.

Therefore, the elastic modulus, including delay elastic modulus $E_{k}$ and instant elastic modulus $E_{k 0}$, of creep test had little relationship with the stress level, indicating that the elastic modules were the constant property of the seedling stem and hardly unchanged with the stress level. As can be observed in Figures 9a and $\mathrm{d}$, the average of the delay elastic modulus $E_{k}$ and the 
instantaneous elastic modulus $E_{k 0}$ were $7.463 \mathrm{MPa}$ and $0.8026 \mathrm{MPa}$, respectively. However, the viscosity coefficient, including delay viscosity coefficient $\eta_{k}$ and viscosity coefficient $\eta_{k 0}$, and the delay time $T_{k}$ were closely related to the stress level, as shown in Figures 9b, 9c, and 9e, they could be fitted with $y=\frac{a}{x}+b$ and had a good correlation coefficient.
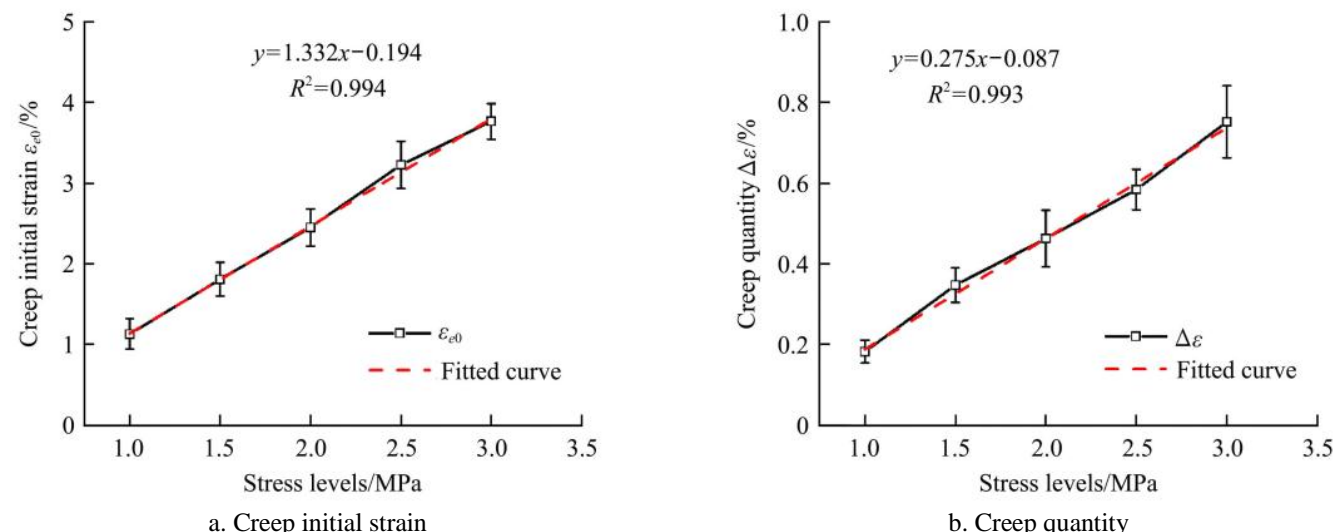

Figure 7 Relationship between creep initial strain, creep quantity and stress levels

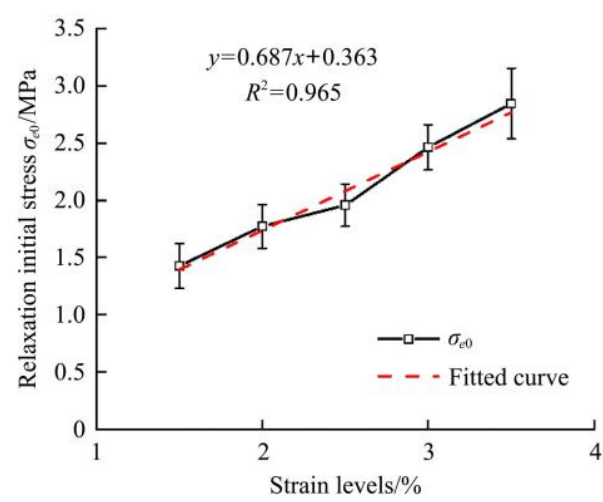

a. Relaxation initial stress

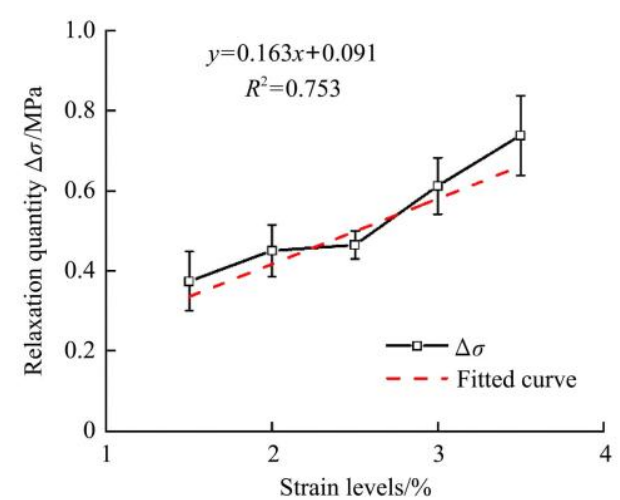

b. Relaxation quantity

Figure 8 Relationship between relaxation initial stress, relaxation quantity and strain levels

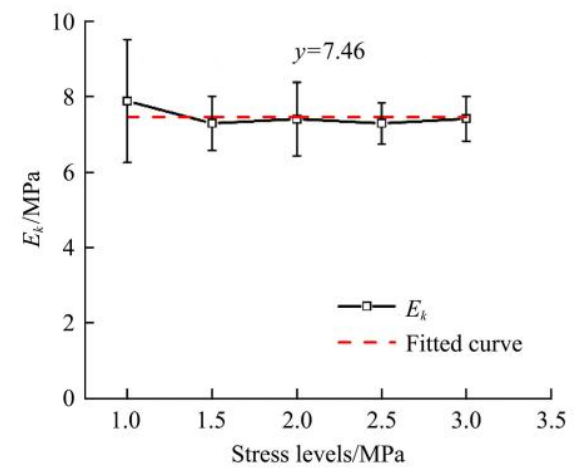

a. Delay elastic modulus $E_{k}$

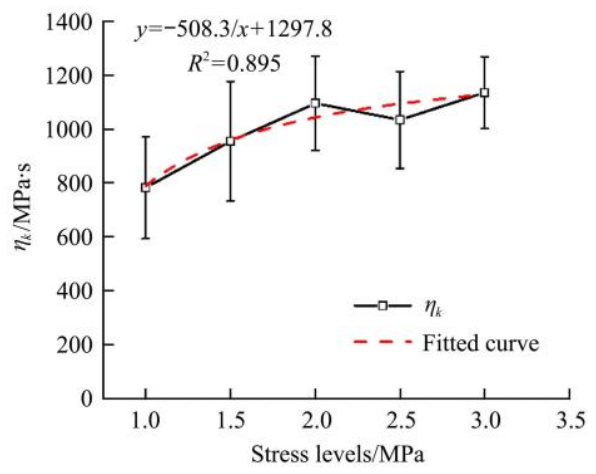

b. Delay viscosity coefficient $\eta_{k}$

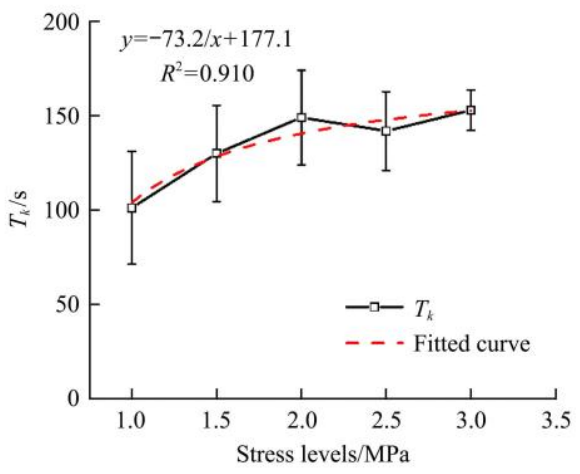

c. Delay time $T_{k}$

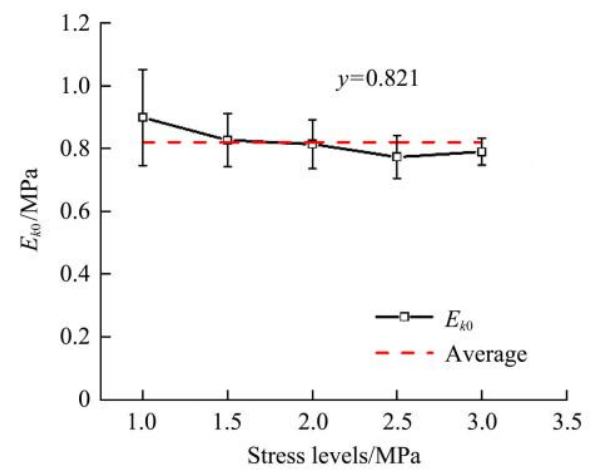

d. Instant elastic modulus $E_{k 0}$

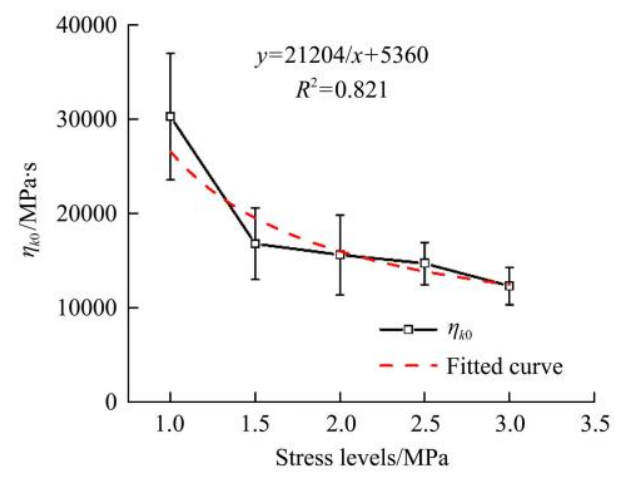

e. Viscosity coefficient $\eta_{k 0}$

Figure 9 Relationships between creep model parameters and stress levels 


\section{Table 3 Creep model parameters at different stress levels}

\begin{tabular}{cccccc}
$\begin{array}{c}\text { Stress } \\
\text { levels } \\
\sigma_{0} / \mathrm{MPa}\end{array}$ & $\begin{array}{c}\text { Delay elastic } \\
\text { modulus } \\
E_{k} / \mathrm{MPa}\end{array}$ & $\begin{array}{c}\text { Delay viscosity } \\
\text { coefficient } \\
\eta_{k} / \mathrm{MPa} \cdot \mathrm{s}\end{array}$ & $\begin{array}{c}\text { Delay } \\
\text { time } \\
T_{k} / \mathrm{s}\end{array}$ & $\begin{array}{c}\text { Instant elastic } \\
\text { modulus } \\
E_{k 0} / \mathrm{MPa}\end{array}$ & $\begin{array}{c}\text { Viscosity } \\
\text { coefficient } \\
\eta_{k 0} / \mathrm{MPa} \cdot \mathrm{s}\end{array}$ \\
\hline 1.0 & $6.366-9.623$ & $548.1-1186.0$ & $69.6-173.8$ & $0.686-1.269$ & $16950-40250$ \\
1.5 & $6.056-8.272$ & $524.0-1319.3$ & $86.5-172.0$ & $0.676-0.978$ & $10930-22010$ \\
2.0 & $6.106-8.779$ & $831.1-1423.7$ & $110.0-200.1$ & $0.706-0.996$ & $10940-26540$ \\
2.5 & $6.224-8.725$ & $752.0-1353.2$ & $99.7-170.5$ & $0.692-0.899$ & $11160-18480$ \\
3.0 & $6.115-8.098$ & $893.4-1359.0$ & $139.0-173.0$ & $0.716-0.858$ & $8081-14510$ \\
\hline
\end{tabular}

\subsection{Relationship between strain components and stress levels}

In the creep process, while the tensile stress staying unchanged, the rice seedling stem strain could be divided into three strain components, including elastic strain $\varepsilon_{e}$, viscoelastic strain $\varepsilon_{v e}$, and plastic strain $\varepsilon_{v}$. Hence, Equation (3) could be rewritten as:

$$
\varepsilon(t)=\varepsilon_{e}+\varepsilon_{e v}+\varepsilon_{v}
$$

where, $\quad \varepsilon_{e}=\frac{\sigma_{0}}{E_{k 0}}, \quad \varepsilon_{e v}=\frac{\sigma_{0}}{E_{k}}\left(1-e^{-t / T_{k}}\right), \quad \varepsilon_{v}=\frac{\sigma_{0} t}{\eta_{k v}}$. When $t=1200 \mathrm{~s}$,

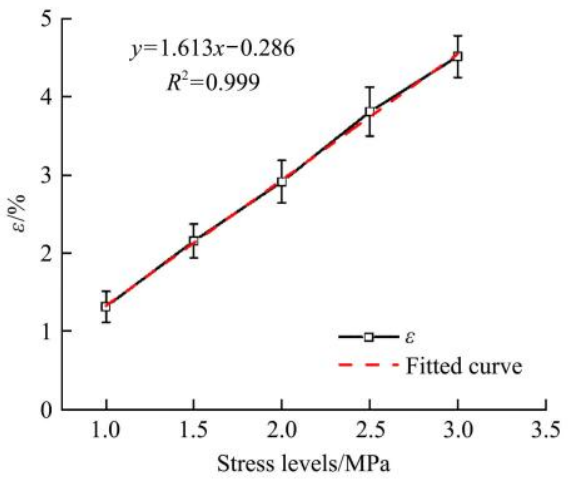

a. Total strain

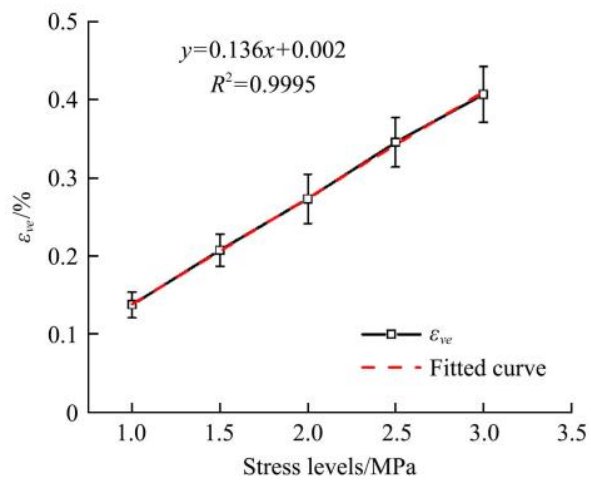

c. Viscoelastic strain strain components at different stress levels were as showed in Table 4. And then, the relationships between strain components and stress levels were analyzed, as showed in Figure 10. In Figure 10, the total strain, elastic strain, viscoelastic strain and plastic strain all linearly increased with the increasing stress. The similar conclusion also occurred in the study of Gao et al. ${ }^{[9]}$

In Table 4 , the percentage of elastic strain in the total strain was the most, taking up $84 \%-87 \%$, and it slightly decreased with the increasing stress, but no obvious difference. As for viscoelastic strain, its percentage was middle of the three, taking up $9 \%-10 \%$, and it also slightly decreased with the increasing stress, but with no obvious difference, just the same as that of the elastic strain. Apparently, the percentage of plastic strain was the least, taking up 3\%-7\%, and it increased with the increasing stress, which was completely opposite to the elastic strain and viscoelastic strain. In other words, the damage to the rice seedling stem increased with the increasing stress.

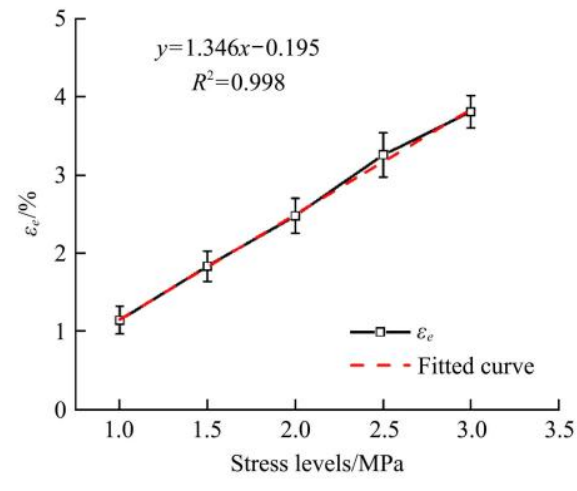

b. Elastic strain

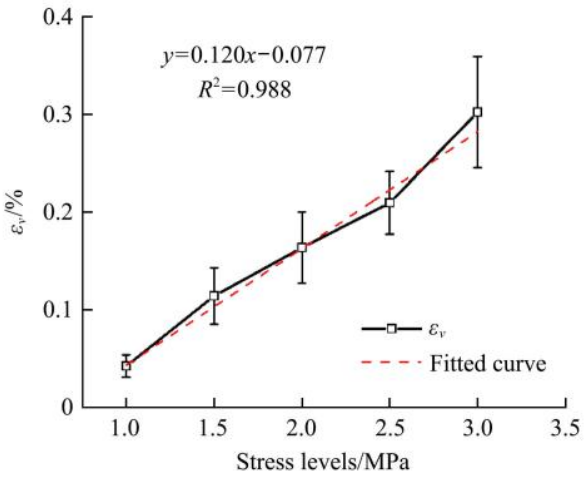

d. Plastic strain

Figure 10 Relationship between strain components and stress levels

Table 4 Comparison of strain components at different stress levels

\begin{tabular}{|c|c|c|c|c|c|c|c|}
\hline \multirow{2}{*}{$\begin{array}{c}\text { Stress levels } \\
\text { /MPa }\end{array}$} & \multicolumn{4}{|c|}{ Strain/\% } & \multicolumn{3}{|c|}{ Percentage $/ \%$} \\
\hline & $\varepsilon$ & $\varepsilon_{e}$ & $\varepsilon_{v e}$ & $\varepsilon_{v}$ & $\varepsilon_{e} / \varepsilon$ & $\varepsilon_{v e} / \varepsilon$ & $\varepsilon_{v} / \varepsilon$ \\
\hline 1.0 & $1.31 \pm 0.20^{\mathrm{e}}$ & $1.14 \pm 0.18^{\mathrm{e}}$ & $0.129 \pm 0.017^{\mathrm{e}}$ & $0.042 \pm 0.012^{\mathrm{d}}$ & $86.88 \pm 1.43^{\mathrm{a}}$ & $9.93 \pm 1.29^{\mathrm{a}}$ & $3.19 \pm 0.59^{\mathrm{c}}$ \\
\hline 2.0 & $2.91 \pm 0.27^{\mathrm{c}}$ & $2.48 \pm 0.22^{\mathrm{c}}$ & $0.273 \pm 0.032^{\mathrm{c}}$ & $0.163 \pm 0.036^{\mathrm{b}}$ & $85.06 \pm 1.12^{\mathrm{b}}$ & $9.39 \pm 0.77^{\mathrm{a}}$ & $5.55 \pm 0.89^{\mathrm{ab}}$ \\
\hline 2.5 & $3.81 \pm 0.31^{\mathrm{b}}$ & $3.26 \pm 0.28^{\mathrm{b}}$ & $0.346 \pm 0.032^{\mathrm{b}}$ & $0.209 \pm 0.032^{\mathrm{b}}$ & $85.42 \pm 0.87^{\mathrm{ab}}$ & $9.08 \pm 0.65^{\mathrm{a}}$ & $5.50 \pm 0.84^{\mathrm{ab}}$ \\
\hline 3.0 & $4.52 \pm 0.27^{\mathrm{a}}$ & $3.81 \pm 0.21^{\mathrm{a}}$ & $0.407 \pm 0.036^{\mathrm{a}}$ & $0.302 \pm 0.036^{\mathrm{a}}$ & $84.34 \pm 1.22^{\mathrm{b}}$ & $9.00 \pm 0.53^{\mathrm{a}}$ & $6.66 \pm 1.00^{\mathrm{a}}$ \\
\hline
\end{tabular}

Note: Different superscript lowercase letters in the same column indicate significant differences at the 0.05 level

\subsection{Relationships between relaxation model parameters and strain levels}

To obtain relaxation model parameters, the curves in Figure 6 were fitted using Equation (4), as showed in Table 5. Using the creep model parameters in Table 5, their relationships with strain levels were analyzed, as seen in Figure 11. In Figure 11a, with the increase of strain $\varepsilon_{0}$, the delay elastic modulus $E_{m 1}$ was basically unchanged, and there was no significant difference in the delayed elastic modulus at each strain level $(p<0.05)$, revealing that the delay elastic modulus had little relationship with the strain level, and it was considered as a constant value, the similar situation also happened in the delay elastic modulus $E_{m 2}$, decay viscosity 
coefficient $\eta_{m 1}$ and instant elastic modulus $E_{m 0}$, as seen in Figures $11 \mathrm{~b}, 11 \mathrm{c}$ and $11 \mathrm{~g}$, respectively. In Figure 11d, it showed that there was a significant difference $(p<0.05)$ in the delay viscosity coefficient $\eta_{m 2}$ at each strain level. With the increase of $\varepsilon_{0}, \eta_{m 2}$ increased with a nonlinear growth rate, and gradually tended to be stable, the similar tendency could be also observed in the delay time $T_{m 1}$ and $T_{m 2}$, as seen in Figures $11 \mathrm{e}$ and 11f, respectively. The situation in Figure 11d showed that $\eta_{m 2}$ was nonlinear positively correlated with the strain level, and the stem had a stronger force to resist deformation and viscous resistance as the strain increased, resulting in the worse fluidity of the internal structure. In Figures 11e and 11f, they showed that the required time, namely relaxation time $T_{m 1}$ and $T_{m 2}$, for the first and the second Maxwell body to reach the strain equilibrium state was also slower as the strain increased.

Consequently, the elastic modulus, including delay elastic modulus $E_{m 1}, E_{m 2}$ and instant elastic modulus $E_{m 0}$, and decay viscosity coefficient $\eta_{m 1}$ of relaxation test had little relationship with the strain levels, indicating that the elastic modulus and $\eta_{m 1}$ in relaxation model were the constant property of the seedling stem and hardly unchanged with the strain levels. And as seen in Figure $11 \mathrm{a}, 11 \mathrm{~b}, 11 \mathrm{c}$ and $11 \mathrm{~g}$, they were $0.104 \mathrm{MPa}, 0.0965 \mathrm{MPa}$, 3.433MPa.s and $0.6268 \mathrm{MPa}$, respectively. On the other hand, the remaining three relaxation model parameters, including the delay viscosity coefficient $\eta_{m 2}$ and relaxation time $T_{m 1}, T_{m 2}$, were closely related to the strain levels, as shown in Figures 11d, e and f, they could be fitted with $y=\frac{a}{x}+b$ and had a good correlation coefficient.

Table 5 Relaxation model parameters at different strain levels

\begin{tabular}{|c|c|c|c|c|c|c|c|}
\hline \multirow{2}{*}{$\begin{array}{c}\text { Strain levels } \\
\varepsilon_{0} / \%\end{array}$} & \multicolumn{2}{|c|}{ Decay elastic modulus/MPa } & \multicolumn{2}{|c|}{ Decay viscosity coefficient/MPa.s } & \multicolumn{2}{|c|}{ Relaxation time/s } & \multirow{2}{*}{$\begin{array}{c}\text { Instant elastic modulus } \\
E_{m 0} / \mathrm{MPa}\end{array}$} \\
\hline & $E_{m 1}$ & $E_{m 2}$ & $\eta_{m 1}$ & $\eta_{m 2}$ & $T_{m 1}$ & $T_{m 2}$ & \\
\hline 1.5 & $0.096-0.204$ & $0.063-0.129$ & $1.66-6.03$ & $11.8-43.1$ & $15.8-34.2$ & $157-357$ & $0.569-0.857$ \\
\hline 2.0 & $0.089-0.137$ & $0.077-0.148$ & $1.81-5.27$ & $16.4-43.3$ & $19.5-50.5$ & $170-352$ & $0.524-0.772$ \\
\hline 2.5 & $0.080-0.108$ & $0.063-0.096$ & $1.99-3.85$ & 20.9-38.4 & $24.8-40.2$ & $251-421$ & $0.488-0.735$ \\
\hline 3.0 & 0.075-0.109 & $0.083-0.123$ & $2.35-4.27$ & $26.6-51.0$ & $31.5-41.4$ & $350-475$ & $0.542-0.692$ \\
\hline 3.5 & $0.072-0.116$ & $0.081-0.119$ & $2.60-4.52$ & $31.8-53.8$ & $34.7-45.5$ & $351-467$ & $0.525-0.724$ \\
\hline
\end{tabular}

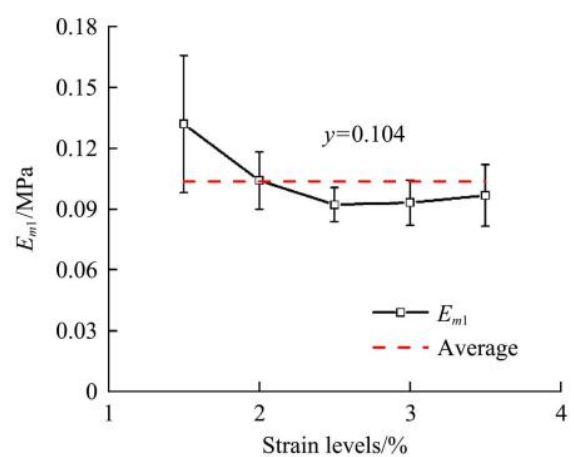

a. Decay elastic modulus $E_{m 1}$

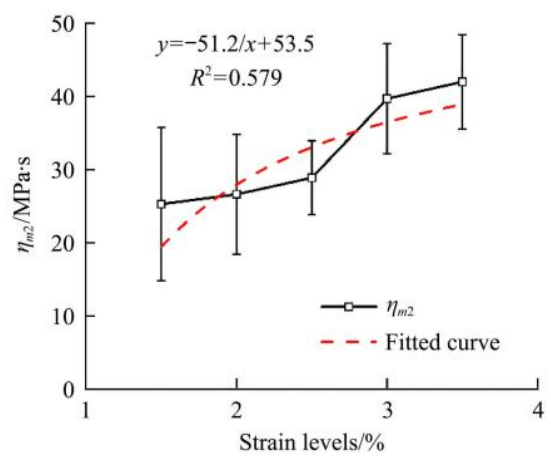

d. Decay viscosity coefficient $\eta_{m 2}$

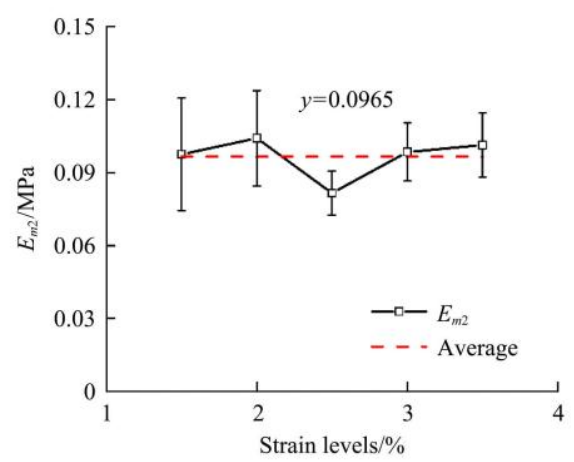

b. Decay elastic modulus $E_{m 2}$

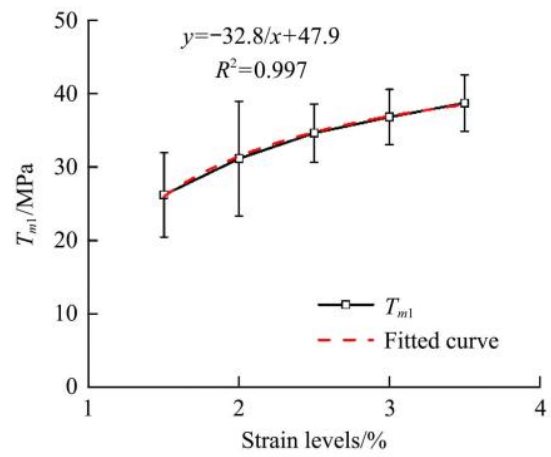

e. Relaxation time $T_{m 1}$

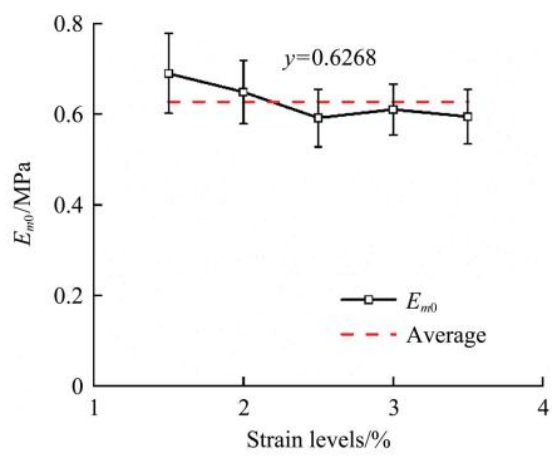

g. Instant elastic modulus $E_{m 0}$

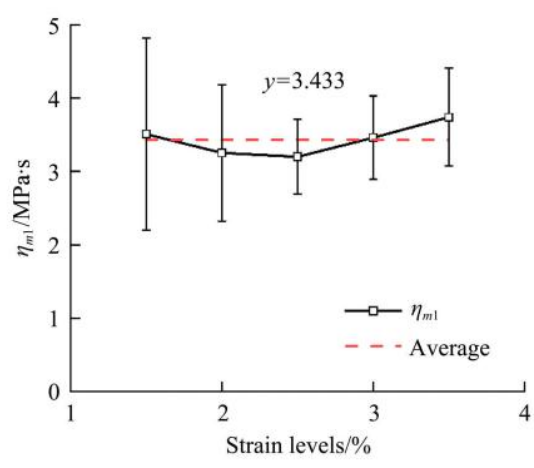

c. Decay viscosity coefficient $\eta_{m 1}$

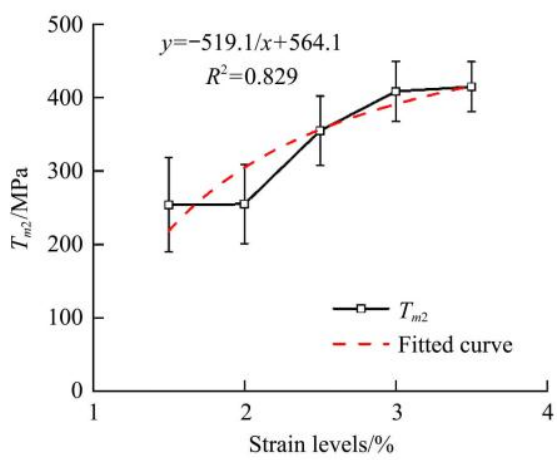

f. Relaxation time $T_{m 2}$

Figure 11 Relationships between relaxation model parameters and strain levels 


\subsection{Relationship between stress components and strain levels}

In the relaxation process, while the tensile deformation staying unchanged, the rice seedling stem strain could be divided into three stress components, including stress in the elastic body $\sigma_{m 0}$, the stress in FMB $\sigma_{m 1}$, and stress in SMB $\sigma_{m 2}$. Hence, Equation (4) could be rewritten as:

$$
\sigma_{t}=\sigma_{m 0}+\sigma_{m 1}+\sigma_{m 2}
$$

where, $\sigma_{m 0}=\varepsilon_{0} E_{m 0}, \sigma_{m 1}=\varepsilon_{0} E_{m 1} e^{-t / T_{m 1}}, \sigma_{m 2}=\varepsilon_{0} E_{m 2} e^{-t / T_{m 2}}$. When $t=0 \mathrm{~s}$ and $t=1200 \mathrm{~s}$, relaxation stress was defined as zero-time stress and final stress, respectively, and their components at different stress levels were as showed in Table 6 and Table 7. Seen in Table 6 and Table 7, zero-time stress in the elastic body was the same as the final. But, the final stress in FMB was almost $0\left(<10^{-10} \mathrm{MPa}\right)$. Subsequently, the relationships between stress components and strain levels were analyzed, as showed in Figure 12. In Figure 12, zero-time stress and final stress of the components increased with the increase of strain.

In Table 6, the percentage of zero-time stress in the elastic body taking up the total stress was the most, about $75 \%-78 \%$, and there was no significant difference between the percentages at different strain levels. As for zero-time stress in FMB and SMB, their percentages were almost similar, about $10 \%-15 \%$. As seen in Table 7, the percentage of the final stress in the elastic body taking up the total stress was more than $99 \%$, almost all the stress of the rice seedling stem was borne by the elastic body. On the contrary, there was a little final stress borne by the FMB and SMB, and the percentage of the final stress in FMB was 0 while that in SMB was less than $1 \%$. Hence, in the relaxation process of the rice seedling stem, it was the process of stress reduction in the FSB and SMB.

Table 6 Comparison of zero-time stress components at different strain levels

\begin{tabular}{|c|c|c|c|c|c|c|c|}
\hline \multirow{2}{*}{$\begin{array}{c}\text { Strain levels } \\
1 \%\end{array}$} & \multicolumn{4}{|c|}{ Zero-time stress $/\left(\times 10^{-3} \mathrm{MPa}\right)$} & \multicolumn{3}{|c|}{ Percentage $/ \%$} \\
\hline & $\sigma$ & $\sigma_{m 0}$ & $\sigma_{m 1}$ & $\sigma_{m 2}$ & $\sigma_{m 0} / \sigma$ & $\sigma_{m 1} / \sigma$ & $\sigma_{m 2} / \sigma$ \\
\hline 1.5 & $1378 \pm 183^{\mathrm{d}}$ & $1034 \pm 132^{\mathrm{e}}$ & $198 \pm 51^{\mathrm{c}}$ & $146 \pm 35^{\mathrm{d}}$ & $75.1 \pm 2.7^{\mathrm{a}}$ & $14.3 \pm 2.6^{\mathrm{a}}$ & $10.6 \pm 2.0^{\mathrm{b}}$ \\
\hline 2.0 & $1713 \pm 169^{c}$ & $1297 \pm 140^{\mathrm{d}}$ & $208 \pm 28^{\mathrm{c}}$ & $208 \pm 39^{c}$ & $75.7 \pm 2.5^{\mathrm{a}}$ & $12.2 \pm 1.7^{\mathrm{ab}}$ & $12.1 \pm 1.7^{\mathrm{ab}}$ \\
\hline 2.5 & $1913 \pm 184^{c}$ & $1479 \pm 159^{c}$ & $230 \pm 21^{\mathrm{bc}}$ & $204 \pm 23^{c}$ & $77.2 \pm 1.4^{\mathrm{a}}$ & $12.1 \pm 1.2^{\mathrm{ab}}$ & $10.7 \pm 0.8^{\mathrm{b}}$ \\
\hline 3.0 & $2405 \pm 189^{b}$ & $1830 \pm 168^{b}$ & $279 \pm 34^{\mathrm{b}}$ & $295 \pm 36^{\mathrm{b}}$ & $76.1 \pm 2.4^{\mathrm{a}}$ & $11.6 \pm 1.0^{\mathrm{b}}$ & $12.3 \pm 1.6^{\mathrm{ab}}$ \\
\hline
\end{tabular}

Note: Different lowercase letters in the same column indicate significant differences at the 0.05 level.

Table 7 Comparison of final stress components at different strain levels

\begin{tabular}{|c|c|c|c|c|c|c|c|}
\hline \multirow{2}{*}{$\begin{array}{c}\text { Strain levels } \\
1 \%\end{array}$} & \multicolumn{4}{|c|}{ Final stress $/\left(\times 10^{-3} \mathrm{MPa}\right)$} & \multicolumn{3}{|c|}{ Percentage/\% } \\
\hline & $\sigma^{\prime}$ & $\sigma_{m 0^{\prime}}$ & $\sigma_{m 1}{ }^{\prime}$ & $\sigma_{m 2^{\prime}}$ & $\sigma_{m 0} / \sigma^{\prime}$ & $\sigma_{m 1}{ }^{\prime} / \sigma^{\prime}$ & $\sigma_{m 2} / \sigma^{\prime}$ \\
\hline 1.5 & $1036 \pm 133^{\mathrm{d}}$ & $1034 \pm 132^{\mathrm{e}}$ & 0 & $1.96 \pm 1.86^{\mathrm{c}}$ & $99.8 \pm 0.2^{\mathrm{a}}$ & 0 & $0.2 \pm 0.2^{\mathrm{c}}$ \\
\hline 2.5 & $1486 \pm 160^{\mathrm{c}}$ & $1479 \pm 159^{c}$ & 0 & $7.21 \pm 3.03^{\mathrm{b}}$ & $99.5 \pm 0.2^{\mathrm{b}}$ & 0 & $0.5 \pm 0.2^{b}$ \\
\hline 3.0 & $1846 \pm 170^{\mathrm{b}}$ & $1830 \pm 168^{\mathrm{b}}$ & 0 & $15.93 \pm 5.27^{\mathrm{a}}$ & $99.1 \pm 0.3^{\mathrm{b}}$ & 0 & $0.9 \pm 0.3^{\mathrm{a}}$ \\
\hline 3.5 & $2100 \pm 210^{\mathrm{a}}$ & $2080 \pm 211^{\mathrm{a}}$ & 0 & $19.80 \pm 5.42^{\mathrm{a}}$ & $99.0 \pm 0.3^{\mathrm{c}}$ & 0 & $1.0 \pm 0.3^{\mathrm{a}}$ \\
\hline
\end{tabular}

Note: Different lowercase letters in the same column indicate significant differences at the 0.05 level.

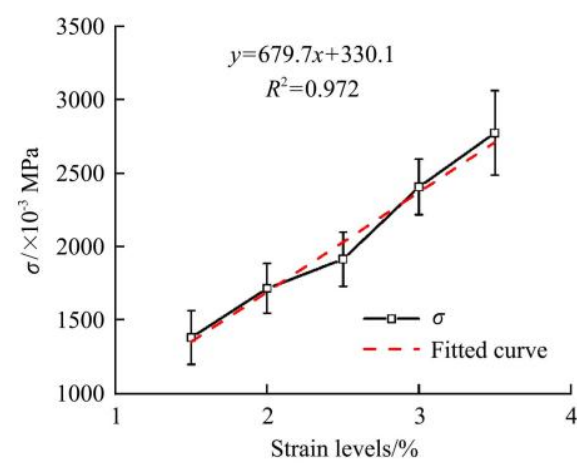

a. Zero-time total stress

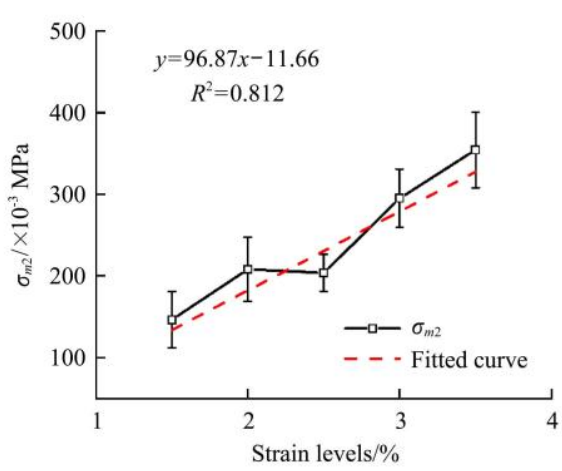

d. Zero-time stress in SMB

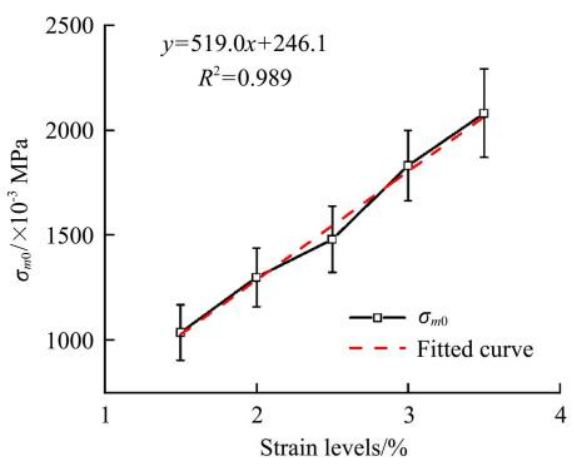

b. Zero-time/ final stress in elastic body

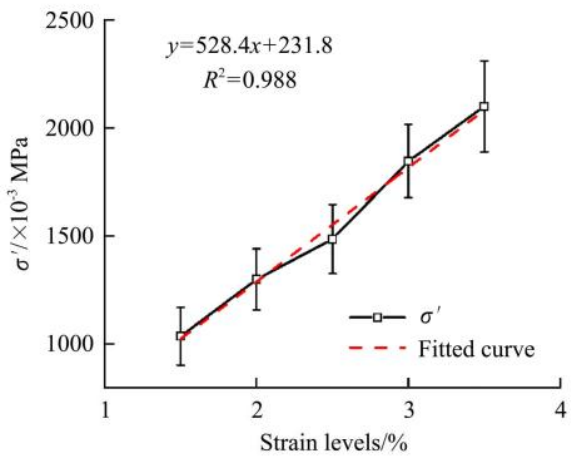

e. Final total stress

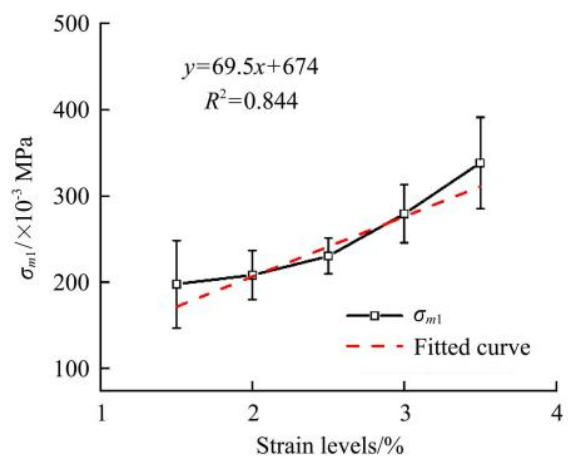

c. Zero-time stress in FMB

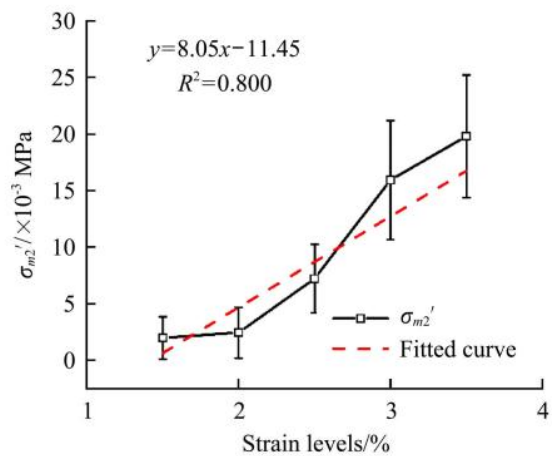

f. Final stress in SMB

Figure 12 Relationship between stress components and stress levels 


\section{Conclusions}

The following conclusions can be drawn:

1) Creep and relaxation tests of stem for rice seedlings grown in plastic cell tray at different test levels can be described by the Burgers 4-element model and the Maxwell 5-element model, respectively.

2) The shapes of creep process curves at different stress levels were similar, as well as the relaxation process curves at different strain levels. And the creep initial strain, creep quantity and the relaxation initial stress, relaxation quantity significantly increased with the increase of stress and strain.

3) Whether creep test or relaxation test on rice seedling stems, there were no significant relationships between the elastic modulus and the test levels. In other words, the elastic modulus is a constant attribute of rice seedling stems. On the contrary, except that viscosity coefficient $\eta_{k v}$ was a constant and $\eta_{m 1}$ decreased with the increasing test levels, other viscosity coefficient and rheological time nonlinearly increased as the test levels increased.

4) In the creep test, elastic strain, viscoelastic strain and plastic strain taking up total stress were $84 \%-87 \%, 9 \%-10 \%$ and $3 \%-7 \%$, respectively. And total stress, elastic strain, viscoelastic strain and plastic strain clearly increased as the stress increased.

5) In the relaxation test, when $t=0 \mathrm{~s}$, the stress in the elastic body, the stress in FMB, and stress in SMB taking up zero-time total stress were $75 \%-78 \%, 10 \%-15 \%$ and $10 \%-15 \%$, respectively. When $t=1200 \mathrm{~s}$, stress in the elastic body, the stress in FMB, and stress in SMB taking up final total stress were more than $99 \%, 0$ and less than $1 \%$, respectively. And zero-time total stress, zero-time/ final stress in the elastic body, zero-time stress in FMB, zero-time stress in SMB, final total stress and final stress in SMB significantly increased as the strain increased.

\section{Acknowledgements}

This research was supported by the National Natural Science Foundation of China (31471418) and Public Welfare Research and Capacity Building Project of Guangdong Province (2014A020208105, 2014A020208018), China.

\section{Nomenclature}

\begin{tabular}{cl}
$M C$ & wet basis moisture content of rice seedling stem $(\%)$ \\
$m_{w}$ & wet weight $(\mathrm{g})$ \\
$m_{d}$ & dry weight $(\mathrm{g})$ \\
$\rho$ & density $\left(\mathrm{g} \cdot \mathrm{cm}^{-3}\right)$ \\
$m$ & weight $(\mathrm{g})$ \\
$a$ & macro axis $(\mathrm{cm})$ \\
$b$ & minor axis $(\mathrm{cm})$ \\
$l$ & measured length \\
$\sigma_{0}$ & initial stress (MPa) \\
$E_{k}$ & delay elastic modulus (MPa) \\
$E_{k 0}$ & instant elastic modulus (MPa) \\
$T_{k}$ & creep delay time (s) \\
$\eta_{k}$ & delay viscosity coefficient $(\mathrm{MPa} \cdot \mathrm{s})$ \\
$\eta_{k v}$ & viscosity coefficient $(\mathrm{MPa} \cdot \mathrm{s})$ \\
$\varepsilon_{0}$ & initial strain $(\%)$ \\
$E_{m 1}$ & decay elastic modulus of the first Maxwell body (FMB, MPa) \\
$E_{m 2}$ & decay elastic modulus of the second Maxwell body (SMB, $\mathrm{MPa})$ \\
$\eta_{\mathrm{m} 1}$ & decay viscosity coefficient of FMB $(\mathrm{MPa} \cdot \mathrm{s})$ \\
$\eta_{\mathrm{m} 2}$ & decay viscosity coefficient of SMB $(\mathrm{MPa} \cdot \mathrm{s})$ \\
\hline &
\end{tabular}

\begin{tabular}{cl}
\hline$T_{m 1}$ & relaxation time of FMB (s) \\
$T_{m 2}$ & relaxation time of SMB (s) \\
$E_{\mathrm{m} 0}$ & instant elastic modulus (MPa) \\
$\varepsilon_{\mathrm{e} 0}$ & creep initial strain (\%) \\
$\Delta \varepsilon$ & creep quantity (\%) \\
$\sigma_{\mathrm{e} 0}$ & relaxation initial stress (MPa) \\
$\Delta \sigma$ & Relaxation quantity (MPa) \\
$\varepsilon_{e}$ & elastic strain (\%) \\
$\varepsilon_{v e}$ & viscoelastic strain (\%) \\
$\varepsilon_{v}$ & plastic strain (\%) \\
$\varepsilon$ & total strain (\%) \\
$\sigma_{m 0}$ & zero-time stress in the elastic body $(\mathrm{MPa})$ \\
$\sigma_{m 1}$ & zero-time stress in FMB (MPa) \\
$\sigma_{m 2}$ & zero-time stress in SMB (MPa) \\
$\sigma$ & total zero-time stress (MPa) \\
$\sigma_{m 0}{ }^{\prime}$ & final stress in FMB (MPa) \\
$\sigma_{m 1}{ }^{\prime}$ & final stress in SMB (MPa) \\
$\sigma_{m 2}{ }^{\prime}$ & total final stress (MPa) \\
$\sigma^{\prime}$ & final stress in the elastic body (MPa) \\
\hline
\end{tabular}

\section{[References]}

[1] Alhaj Hamoud Y, Guo X, Wang Z, Shaghaleh H, Chen S, Hassan A, et al. Effects of irrigation regime and soil clay content and their interaction on the biological yield, nitrogen uptake and nitrogen-use efficiency of rice grown in southern China. Agricultural Water Management, 2019; 213(C): 934-946.

[2] Prasad R, Shivay Y S, Kumar D. Current status, challenges, and opportunities in rice production. In: Chauhan B, Jabran K, Mahajan G (Ed.). Rice Production Worldwide, Cham: Springer, 2017; pp.1-32.

[3] National Bureau of Statistics of China. China Statistical Yearbook 2018 Beijing: China Statistics Press, 2018.

[4] Ma R J, Xiao J Q, Zheng P F, Zhang Y L, Chen Y, Qiu Z. Experimenta study on characteristics of creep and stress relaxation for rice seedling stem raised in cell tray. Transactions of the CSAE, 2018; 34(13): 43-53. (in Chinese)

[5] Ma R J, Ou Y G, Shao Y J. Study on manipulator of a seedling throwing device. Transactions of the CSAM, 2002; 33(1): 36-38, 42. (in Chinese)

[6] Watanabe H, Saigusa M, Morita S. Identification of casparian bands in the mesocotyl and lower internodes of rice (Oryza sativa L.) seedlings using fluorescence microscopy. Plant Production Science, 2015; 9(4): 390-394.

[7] Niklas K J. Plant biomechanics: An engineering approach to plant form and function. International Journal of Plant Sciences, 1992(4): 1-47. doi: hdl.handle.net/1813/28577.

[8] Abe K, Yano H. Comparison of the characteristics of cellulose microfibril aggregates of wood, rice straw and potato tuber. Cellulose, 2009; 16(6): 1017-1023.

[9] Gao H, Wang F, Shao Z. Study on the rheological model of Xuan paper. Wood Science and Technology, 2015; 50(2): 427-440.

[10] Song J N, Wang P, Wei W J, Wang L C. Experimental research on tensfle strength of rice seedlings and force of pulling out seedlings from trays. Transactions of the CSAE, 2003; 19(6): 10-13. (in Chinese)

[11] Ma R, Ou Y, Zhao Z, Mao Z. Experimental study on fracture mechanic characteristics of rice seedlings sprouted in plastic cell-tray. Transactions of the CSAM, 2004; 35(1): 56-59,68.

[12] Ishimaru K, Togawa E, Ookawa T, Kashiwagi T, Madoka Y, Hirotsu N. New target for rice lodging resistance and its effect in a typhoon. Planta, 2008; 227(3): 601-609.

[13] Zhang F Z, Jin Z X, Ma G H, Shang W N, Liu H Y, Xu M L, et al. Relationship between lodging resistance and chemical contents in culms and sheaths of japonica rice during grain filling. Rice Science, 2010; 17(4): 311-318.

[14] Gui M Y, Wang D, Xiao H H, Tu M, Li F L, Li W C, et al. Studies of the relationship between rice stem composition and lodging resistance. Journal of Agricultural Science, 2018; 156(3): 387-395.

[15] Ghofrani M, Mokaram K N, Ashori A, Torkaman J. Fiber-cement composite using rice stalk fiber and rice husk ash: Mechanical and physical properties. Journal of Composite Materials, 2014; 49(26): 3317-3322. 
[16] Engelund E T, Salmén L. Tensile creep and recovery of Norway spruce influenced by temperature and moisture. Holzforschung, 2012; 66(8): 959-965.

[17] Moutee M, Fortin Y, Laghdir A, Fafard M. Cantilever experimental setup for rheological parameter identification in relation to wood drying. Wood Science and Technology, 2009; 44(1): 31-49.

[18] Lagafta R, Babiak M, Krakovsky A. Creep parameters of spruce wood in high temperature environment. Maderas Cienc Tecnol, 2008; 10(1): $19-24$.

[19] Chen J H, Zhao N, Fu N, Li D, Wang L J, Chen X D. Mechanical properties of hulless barley stem with different moisture contents. International Journal of Food Engineering, 2019; 15(1-2): 1-10. doi: 10.1515/ijfe-2018-0033.

[20] Chen L J, Liao N, Xing L, Han L J. Description of wheat straw relaxation behavior based on a fractional-order constitutive model. Agronomy Journal, 2013; 105(1): 134-124.
[21] Zhao W, Fang Y, Zhang Q A, Guo Y, Gao G, Yi X. Correlation analysis between chemical or texture attributes and stress relaxation properties of 'Fuji' apple. Postharvest Biology and Technology, 2017; 129: 45-51.

[22] Wang J. Anisotropic relaxation properties of pear. Biosystems Engineering, 2003; 85(1): 59-65.

[23] Sikame Tagne N R, Ndapeu D, Nkemaja D, Tchemou G, Fokwa D, Huisken $\mathrm{W}$, et al. Study of the viscoelastic behaviour of the Raffia vinifera fibres. Industrial Crops and Products, 2018; 124:572-581.

[24] Ozturk O K, Takhar P S. Stress relaxation behavior of oat flakes Journal of Cereal Science, 2017; 77: 84-89.

[25] Wang P Y. The rheological behaviour of poplar wood in compression perpendicular to grain II. Plasticity. Scientia Silvae Sinicae, 1987; 23(3): 356-362.

[26] Wang P Y. The rheological behaviour of poplar wood in compression perpendicular to grain I. Viscoelasticity. Scientia Silvae Sinicae, 1987; 23(2): 182-190. (in Chinese) 